\title{
Affinity for Thyroid Hormone and Estrogen Receptors of Hydroxylated Polybrominated Diphenyl Ethers
}

\author{
Shigeyuki Kitamura, ${ }^{*, a, b}$ Seiji Shinohara, ${ }^{a}$ Eri Iwase, ${ }^{a}$ Kazumi Sugihara, ${ }^{a}$ Naoto Uramaru,,${ }^{a, b}$ \\ Hidenari Shigematsu, ${ }^{b}$ Nariaki Fujimoto, ${ }^{a}$ and Shigeru Ohta ${ }^{a}$ \\ ${ }^{a}$ Graduate School of Biomedical Sciences, Hiroshima University, Kasumi 1-2-3, Minami-ku, Hiroshima 734-8553, Japan and ${ }^{b}$ Nihon \\ Pharmaceutical University, Komuro 10281, Ina-machi, Saitama 362-0806, Japan
}

(Received August 5, 2008; Accepted August 13, 2008)

The affinity for thyroid hormone receptor (TR) of polybromodiphenyl ethers (PBDEs) and hydroxylated PBDEs was examined. 4-Hydroxy$2,2^{\prime}, 3,4^{\prime}, 5$-pentabromodiphenyl ether (4-OH-BDE90) and 3-hydroxy-2, $2^{\prime}, 4,4^{\prime}$-tetrabromodiphenyl ether (3-OH-BDE-47) markedly inhibited the binding of triiodothyronine $\left(1 \times 10^{-10} \mathrm{M}\right)$ to $\mathrm{TR}$ in the concentration range of $1 \times 10^{-6}-1 \times 10^{-4} \mathrm{M} .2,3,4,5,6-$ Pentabromophenol (PBP) also showed an inhibitory effect at $1 \times 10^{-5}-1 \times 10^{-4} \mathrm{M}$. However, $2,2^{\prime}, 3,4,4^{\prime}, 5^{\prime}-$ hexabromodiphenyl ether (BDE-138), decabromodiphenyl ether (DBDE), 4-methoxy-2,2',3,4',5pentabromodiphenyl ether (4-MeO-BDE-90), 4'hydroxy-2,2', 4,5' -tetrabromodiphenyl ether ( $4^{\prime}$-OHBDE-49), 4-hydroxy-2,2',3,4' -tetrabromodiphenyl ether (4-OH-BDE-42), 4'-hydroxy-2,2',4-tribromodiphenyl ether (4'-OH-BDE-17), $3^{\prime}$-hydroxy2,4-dibromodiphenyl ether (3'-OH-BDE-7), 2,4,6tribromophenol (TBP) and tetrabromohydroquinone (TBHQ) did not show affinity for TR. In contrast, 4'-OH-BDE-17 and 3'-OH-BDE-7 exhibited estrogenic activity in estrogen-responsive reporter assay using MCF-7 cells at the concentration of $1 \times 10^{-5} \mathrm{M}$. However, adjacent bromo substitution of 3- or 4-hydroxylated PBDEs markedly decreased the estrogenic activity. These results suggest that hydroxylated PBDEs act as thyroid hormone-like agents, as well as estrogens, that a 4- or 3-hydroxyl group in PBDEs is essential for thyroid hormonal and estrogenic activities, and that adjacent dibromo substitution favors thyroid hormonal activity, but not estrogenic activity.

Key words — polybrominated diphenyl ether, thyroid hormonal activity, estrogenic activity, hydroxylated

\footnotetext{
** To whom correspondence should be addressed: Nihon Pharmaceutical University, Komuro 10281, Ina-machi, Saitama 362-0806, Japan. Tel.: +81-48-721-1155; Fax: +81-48-7216973; E-mail: kitamura@nichiyaku.ac.jp
}

polybrominated diphenyl ether

\section{INTRODUCTION}

Brominated flame retardants are widely used throughout the world in electronic circuit boards and other electronic equipment. ${ }^{1-5)}$ Polybrominated diphenyl ethers (PBDEs) and tetrabromobisphenol A (TBBPA) have been detected in environmental samples such as sediments, fish, birds, and also in human breast milk and blood. ${ }^{6-14)}$ Exposure to PBDEs can lead to thyroid hormone disturbances and neurotoxicity in wildlife and humans. ${ }^{15-19)}$

It has been reported that some PBDEs and TBBPA have estrogenic, anti-androgenic and antiprogesteronic activities in vitro. ${ }^{19-22)}$ Ceccatelli et al. reported that a PBDE, PBDE 99, can cause disruption of estrogenic action in vivo in rats. $\left.{ }^{23}\right)$ Richardson et al. reported that BDE 47 caused disruption of thyroid hormonal action in mice in vivo. ${ }^{24)}$ Lilienthal et al. also reported an effect of PBDE 99 on sexual development and sexually dimorphic behavior in rats. ${ }^{25}$ Several PBDEs have been reported to cause thyroid hormone disruption. ${ }^{26-28)}$ It has been suggested that hydroxylated PBDEs may disrupt thyroid hormone status, because of their structural similarity to thyroid hormone. Hydroxylated PBDEs may have high binding affinity for the serum thyroid hormone binding protein transthyretin (TTR), thyroid hormone receptor (TR), thereby displacing the natural ligand. However, the exact mechanisms of interference with thyroid hormonal action are not fully understood.

In this report, we tested with the thyroid hormonal and estrogenic activities of PBDEs, including their hydroxylated derivatives, as determined by means of binding assay with TR from the rat pituitary cell line MtT/E-2 and estrogen- 


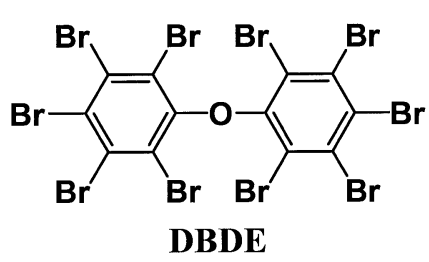<smiles>Brc1cc(Br)c(Oc2ccc(Br)c(Br)c2Br)cc1Br</smiles>

BDE-138<smiles>Oc1ccc(Oc2ccc(Br)cc2Br)c(Br)c1</smiles><smiles>Oc1cc(Br)c(Oc2ccc(Br)cc2Br)cc1Br</smiles><smiles>Oc1c(Br)c(Br)c(Br)c(Br)c1Br</smiles><smiles>Oc1c(Br)ccc(Oc2ccc(Br)cc2Br)c1Br</smiles><smiles>Oc1c(Br)cc(Oc2ccc(Br)cc2Br)c(Br)c1Br</smiles><smiles>Oc1c(Br)cc(Br)cc1Br</smiles><smiles>Oc1cccc(Oc2ccc(Br)cc2Br)c1</smiles>

3'-OH-BDE-7<smiles>Oc1ccc(Oc2ccc(Br)cc2Br)c(Br)c1Br</smiles><smiles>COc1c(Br)cc(Oc2ccc(Br)cc2Br)c(Br)c1Br</smiles><smiles>Oc1c(Br)c(Br)c(Br)c(Br)c1Br</smiles>

Fig. 1. Structures of PBDEs and Hydroxylated PBDEs Used in this Study

responsive element (ERE)-luciferase reporter assay using MCF-7 cells. As substrates, we used 12 PBDEs and related compounds, 2,2',3,4,4', $5^{\prime}$ hexabromodiphenyl ether (BDE-138), decabromodiphenyl ether (DBDE), 4-hydroxy$2,2^{\prime}, 3,4^{\prime}$-tetrabromodiphenyl ether (4-OH-BDE42), 4'-hydroxy-2,2',4-tribromodiphenyl ether (4'-OH-BDE-17), 4-hydroxy-2,2',3,4',5-pentabromodiphenyl ether (4-OH-BDE-90), 3-hydroxy2,2',4,4'-tetrabromodiphenyl ether (3-OH-BDE47), 4'-hydroxy-2,2',4,5' -tetrabromodiphenyl ether (4'-OH-BDE-49), 3'-hydroxy-2,4-dibromodiphenyl ether (3'-OH-BDE-7), 4-methoxy-2,2',3,4',5pentabromodiphenyl ether (4-MeO-BDE-90), 2,3,4,5,6-pentabromophenol (PBP), 2,4,6-tribromophenol (TBP) and tetrabromohydroquinone (TBHQ) (Fig. 1). We found that hydroxylated PBDEs exhibit significant thyroid hormonal activity, as well as estrogenic activity.

\section{MATERIALS AND METHODS}

Chemicals — ${ }^{125} \mathrm{I}-\mathrm{T} 3\left(3,5,3^{\prime}{ }^{125} \mathrm{I}\right.$, radiochemical purity > 95\%, 28.8 TBq/mmol) was purchased from NEN Life Science Products (Boston, MA,
U.S.A.). Hydroxylated PBDEs and other PBDEs were obtained from Accu Standard (New Haven, CT, U.S.A.), and $17 \beta$-estradiol (E2) was from Sigma (St. Louis, MO, U.S.A.). Test compounds were solubilized in dimethyl sulfoxide, and the assay was conducted in $0.1 \%$ dimethyl sulfoxide solution. Cells of a human breast cancer cell line, MCF7, were obtained from the Health Science Research Resources Bank (Osaka, Japan). The rat pituitary cell line, MtT/E-2, was established in our laboratory. ${ }^{29)}$

Competitive Binding Assay to TR - Nuclear extracts of $\mathrm{MtT} / \mathrm{E}$ were used for the assay, since this cell line expresses large amounts of TR. MtT/E2 cells were homogenized in $0.32 \mathrm{M}$ sucrose solution containing $3 \mathrm{mM} \mathrm{MgCl} 2$ and $1 \mathrm{mM}$ dithiothreitol, and centrifuged at $700 \mathrm{~g}$ for $10 \mathrm{~min}$. The pellets were resuspended in $2.4 \mathrm{M}$ sucrose with $\mathrm{MgCl}_{2}$ and centrifuged at $53000 \mathrm{~g}$ for $45 \mathrm{~min}$. The resulting nuclear pellets were resuspended in TMDS buffer ( $2 \mathrm{mM}$ Tris- $\mathrm{HCl}, 3 \mathrm{mM} \mathrm{MgCl} 2,1 \mathrm{mM}$ dithiothreitol, $0.32 \mathrm{M}$ sucrose, $\mathrm{pH}$ 7.4). Various concentrations of test chemicals and $3 \mathrm{nM}{ }^{125} \mathrm{I}-\mathrm{T} 3$ were incubated in $0.2 \mathrm{ml}$ of the nuclear suspension at $37^{\circ} \mathrm{C}$ for $40 \mathrm{~min}$. After incubation, $0.25 \mathrm{ml}$ of $2 \%$ Triton $\mathrm{X}-100$ was added to terminate the reaction, and the mixture 

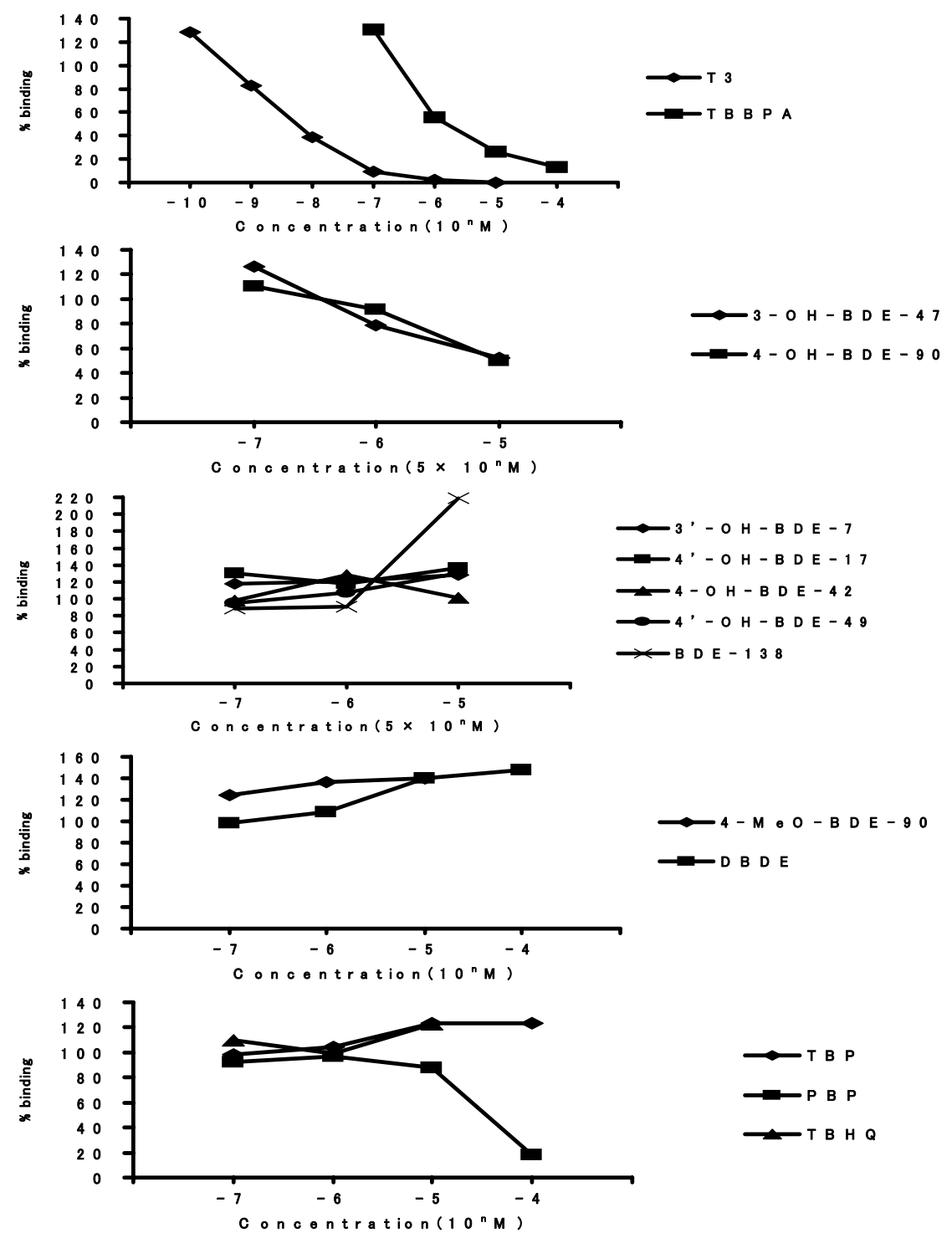

Fig. 2. Binding Assay of Test Compounds to Thyroid Hormone Receptor

Each value represents the mean of triplicate determinations. Activity was expressed relative to the control with no added test compound. T3; L-3,5,3'-triiodothyronine, TBBPA; tetrabromobisphenol A, 3-OH-BDE-47; 3-hydroxy-2,2' ,4,4'-tetrabromodiphenyl ether, 4-OH-BDE-90; 4-hydroxy2,2',3,4',5-pentabromodiphenyl ether, 3'-OH-BDE-7; 3'-hydroxy-2,4-dibromodiphenyl ether, 4'-OH-BDE-17; 4'-hydroxy-2,2',4-tribromodiphenyl ether, 4-OH-BDE-42; 4-hydroxy-2,2',3,4'-tetrabromodiphenyl ether, 4'-OH-BDE-49; 4'-hydroxy-2,2',4,5'-tetrabromodiphenyl ether, BDE-138;

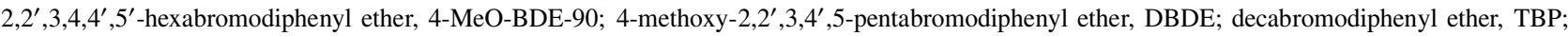
2,4,6-tribromophenol, PBP; 2,3,4,5,6-pentabromophenol, TBHQ; tetrabromohydroquinone.

was centrifuged at $1000 \mathrm{~g}$ for $10 \mathrm{~min}$. The pellets were washed 2 times with $1 \mathrm{ml}$ of TMDS buffer and the supernatant was removed. Radioactivity of the pellets was counted with a gamma counter (Wallac Wizard 1480, Perkin Elmer Life Sciences, Boston, MA, U.S.A.).

Assay of Estrogenic Activity of Hydroxylated PBDEs and Related Compounds - EREluciferase reporter assay using MCF-7 cells was performed according to the previously reported method..$^{30)}$

\section{RESULTS}

Competitive Binding Assay for TR of Hyydroxylated PBDEs and Related Compounds

The inhibitory effects of PBDEs and hydroxylated PBDEs on binding of T3 to TR were examined. T3 competitively inhibited the binding of ${ }^{125} \mathrm{I}$ T3 $\left(1 \times 10^{-10} \mathrm{M}\right)$ to TR in the range of $1 \times 10^{-9}$ $1 \times 10^{-6} \mathrm{M}$, and TBBPA also showed an inhibitory effect at $10^{-6}-10^{-4}$ M. 4-OH-BDE-90 and 3-OHBDE-47 also markedly inhibited the binding of 


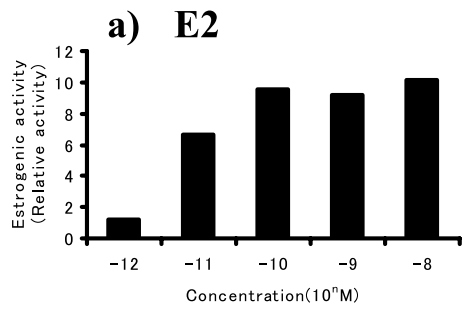

d) 4'-OH-BDE-17

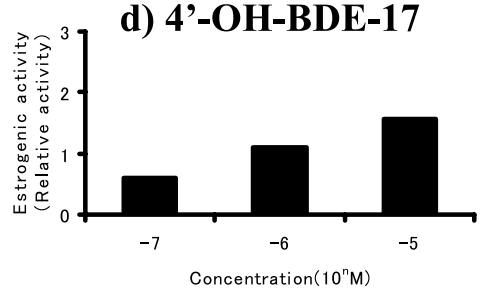

g) 4'-OH-BDE-49

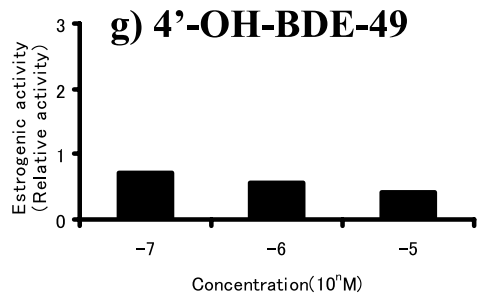

b) BDE-138

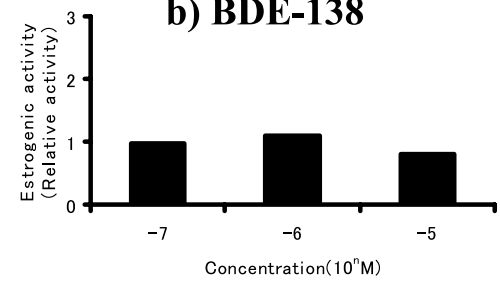

e) 4-OH-BDE-42
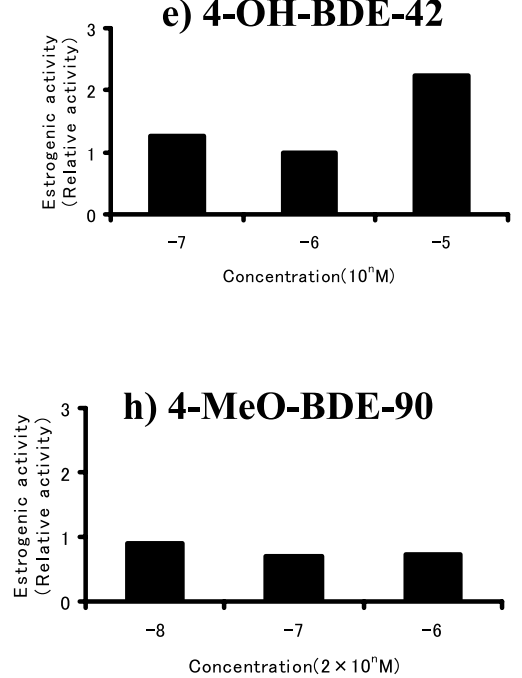

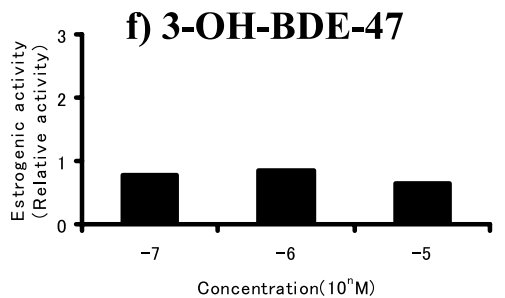

c) 3'-OH-BDE-

7

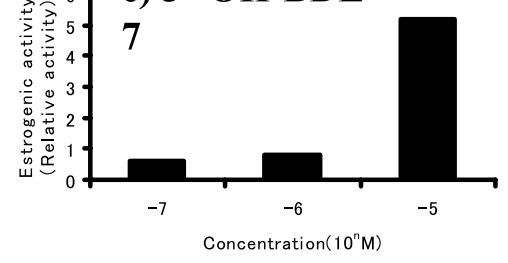

f) 3-OH-BDE-47

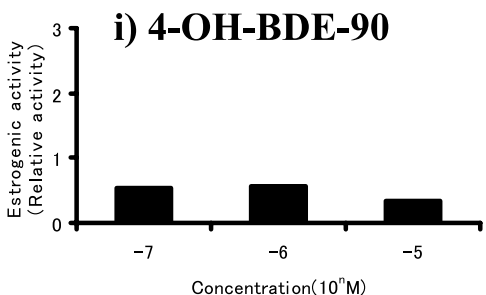

Fig. 3. Estrogenic Activity of PBDEs and Related Compounds in ERE-luciferase Reporter Assay Using MCF-7 Cells

Each value represents the mean of triplicate determinations. Estrogenic activity of PBDEs was expressed as relative activity with respect to the control using MCF-7 cells. E2; $17 \beta$-estradiol, BDE-138; 2,2',3,4,4',5'-hexabromodiphenyl ether, $3^{\prime}$-OH-BDE-7; $3^{\prime}$-hydroxy-2,4-dibromodiphenyl ether, 4'-OH-BDE-17; 4'-hydroxy-2,2',4-tribromodiphenyl ether, 4-OH-BDE-42; 4-hydroxy-2,2',3,4'-tetrabromodiphenyl ether, 3-OH-BDE-47; 3-

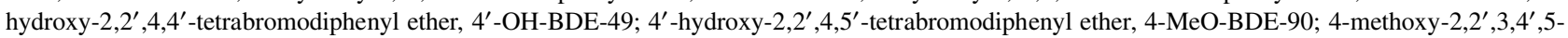
pentabromodiphenyl ether, 4-OH-BDE-90; 4-hydroxy-2,2',3,4',5-pentabromodiphenyl ether.

${ }^{125} \mathrm{I}-\mathrm{T} 3$ to the receptor in the concentration range of $1 \times 10^{-6}-1 \times 10^{-4} \mathrm{M}$. PBP showed an inhibitory effect at $1 \times 10^{-5}-1 \times 10^{-4} \mathrm{M}$. BDE-138, DBDE, 4-MeO-BDE-90, 4'-OH-BDE-49, 4-OH-BDE-42, $4^{\prime}$-OH-BDE-17, 3'-OH-BDE-7, TBP and TBHQ showed little or no affinity. Elevated binding affinity was observed for hydroxylated PBDEs with bromine substitution at both adjacent positions to the hydroxyl group. 4-Hydroxy-PBDEs brominated at the 3- or 5-position, but not both, showed little activity. Hydroxylated PBDEs with no adjacent bromine substitution of the phenyl ring, and 4methoxy-PBDEs also showed little affinity (Fig. 2).

\section{Estrogenic Activity of PBDEs and Hydroxylated PBDEs}

4'-OH-BDE-17 and $3^{\prime}$-OH-BDE-7 exhibited estrogenic activity in estrogen-responsive reporter assay using MCF-7 cells in the concentration range of $1 \times 10^{-6}-1 \times 10^{-5} \mathrm{M}$. However, no estrogenic activity of other 4-hydroxy-PBDEs or PBDEs was observed. These experiments indicate that a hydroxyl group of PBDEs is essential for estrogenic activity, but 3- or 4-hydroxyl PBDEs with orthobromine substituents show decreased estrogenic activity (Fig. 3).

\section{DISCUSSION}

In this study, the thyroid hormonal potency of PBDEs was examined, in view of their structural resemblance to the thyroid hormones. We found that hydroxylated PBDEs show thyroid hormonedisrupting activity through interaction with TR, though PBDEs do not. Recently, thyroid hormonedisrupting action of some PBDEs and hydroxyPBDEs has been discussed. ${ }^{31)}$ Meerts et al. reported that some PBDEs exhibited binding capability to TTR after metabolic conversion by rat liver microsomes. ${ }^{32)}$ They suggested that the hydroxylated PBDEs thus formed exhibited the binding ac- 
tivity with TTR. Hallgren and Danerud also suggested that hydroxylated metabolites of $2,2^{\prime}, 4,4^{\prime}$ tetrabromodiphenyl ether bind TTR in rats in vivo. ${ }^{15)}$ Schriks et al. reported that synthetic T2, T3 and T4-like PBDEs show thyroid hormone-like activity. ${ }^{33)}$ Dietrich et al. reported that some brominated thyroxine analogues have thyroid hormonal activity. ${ }^{34)}$ Hamers et al. reported that some PBDEs disrupt the endocrine system by binding to TTR, and exhibit progesterone receptor (PR)- and androgen receptor (AR)-antagonistic effects in the presence of T3. ${ }^{19)}$ We present here direct evidence that some hydroxylated PBDEs bind to TR.

We found that PBDEs substituted with two bromo atoms adjacent to the hydroxyl group on an aromatic ring show thyroid hormonal activity, though other PBDEs do not. A 3- or 4-hydroxyl group and two adjacent bromo substituents on the phenyl group seem to be essential structural factors for binding to TR. In this respect, the compounds apparently resemble T4, rather than T3. However, the atomic size of bromine is much smaller than that of iodine. In view of the affinity of hydroxylated PBDEs for TR, two adjacent bromo substituents may be favorable for binding to TR. We also recognized a similar structural requirement for TR affinity in a brominated bisphenol A, TBBPA, and also chlorinated and methylated bisphenol A. ${ }^{20)} 3,5$-Substituents of bisphenol A are also necessary for thyroid hormonal activity. Another brominated phenyl ring substituted at the 1position of the phenyl ring bearing the 3- or 4hydroxyl group also seems to be necessary for high binding affinity for TR, because TBHQ and TBP showed weaker activity. Hydroxy-polychlorinated biphenyls (PCBs) were also reported to show both estrogenic and thyroid hormone-disrupting activities. ${ }^{35-38)}$ Iwasaki et al. reported that 4-hydroxy$2^{\prime}, 3,3^{\prime}, 4^{\prime}, 5^{\prime}$-pentachlorobiphenyl acts as an antagonist by suppressing the interaction of TR and a coactivator. ${ }^{39)}$ We also reported that a 4-hydroxyl group and adjacent 3,5-dichloro substituents on the phenyl group seem to be essential structural factors for binding to TR, in agreement with the present findings. ${ }^{35)}$ In contrast, we found that $4-\mathrm{OH}-$ $2^{\prime}, 4^{\prime}, 6^{\prime}$-trichlorobiphenyl, a 4-hydroxy-PCB without 3,5-chlorine atoms, is estrogenic in an estrogenresponsive reporter test using human breast cancer cell line MCF-7. However, 4-hydroxy-3,5dichlorinated biphenyl exhibited little estrogenic activity. ${ }^{35)}$ These results are also consistent with the estrogenic activity of hydroxylated PBDEs found in this study.

There are other mechanisms through which environmental contaminants may interact with the thyroid hormone system. These include direct toxicity at the thyroid gland, which can lead to decreased synthesis of thyroid hormones, disturbance of thyroid hormone metabolism, and interaction with thyroid hormone transport proteins. ${ }^{40-44)}$ Richardson et al. demonstrated the induction of glucuronidation and thyroid hormone transporter as mechanisms leading to a decreased level of thyroid hormone after administration of BDE 47 to mice. ${ }^{24)}$ PBDE-99 reduced the thyroxin level in rat dames after a single gestational exposure, and also reduced hepatic enzyme activity. ${ }^{45}$ ) Hydroxylated PBDEs bind to human TTR and thyroid-binding globulin in vitro. ${ }^{32)}$ In the current study, it was shown that hydroxylated PBDEs interact with TR. These results suggest that hydroxylated PBDEs have the potential to disrupt thyroid hormonal activity in vivo by interaction with TR, besides binding with TTR. Further work is necessary to assess the in vivo endocrinedisrupting action of hydroxylated PBDEs, taking into account the other thyroid hormone-disrupting actions of these compounds. Thyroid hormonal and estrogenic activities of hydroxylated PBDEs observed in vitro may reflect endocrinal toxicity in vivo. We demonstrated that amphibian metamorphosis is suppressed by TBBPA and related compounds. ${ }^{46,47)}$

In conclusion, the structural requirements of hydroxylated PBDEs for thyroid hormonal activity are a 3- or 4-hydroxyl group and two adjacent bromine substitutions adjacent to the hydroxyl group. The requirement for estrogenic activity is a 3- or 4hydroxyl group, but adjacent bromine substitution of hydroxy-PBDEs reduces the estrogenic activity.

Acknowledgements This work was supported by a Grant-in-Aid for Scientific Research on Priority Areas from the Japanese Ministry of Education, Science, Sports and Culture, and a Grant-in-Aid for Scientific Research from the Japanese Ministry of the Environment.

\section{REFERENCES}

1) Alaee, M. and Wenning, R. J. (2002) The significance of brominated flame retardants in the environment-current understanding, issues and challenges. Chemosphere, 46, 579-582. 
2) Darnerud, P. O., Eriksen, G. S., Johannesson, T., Larsen, P. B. and Viluksela, M. (2001) Polybrominated diphenyl ethers: Occurrence, dietary exposure, and toxicology. Environ. Health Perspect., 109, 49-68.

3) Darnerud, P. O. (2003) Toxic effects of brominated flame retardants in man and in wildlife. Environ. Int., 29, 841-853.

4) de Wit, C. A. (2002) An overview of brominated flame retardants in the environment. Chemosphere, 46, 583-624.

5) Sjödin, A., Patterson, D. G. and Bergman, A. (2003) A review on human exposure to brominated flame retardants-particularly polybrominated diphenyl ethers. Environ. Int., 29, 829-839.

6) Sjödin, A., Carlsson, H., Thuresson, K., Sjölin, S., Bergman, A. and Östman, C. (2001) Flame retardants in indoor air at an electronics recycling plant and at other work environments. Environ. Sci. Technol., 35, 448-454.

7) Thomsen, C., Janak, K., Lundanes, E. and Becher, G. (2001) Determination of phenolic flameretardants in human plasma using solid-phase extraction and gas chromatography-electron-capture mass spectrometry. J. Chromatogr. B, 750, 1-11.

8) Thomsen, C., Lundanes, E. and Becher, G. (2002) Brominated flame retardants in archived serum samples from Norway: A study on temporal trends and the role of age. Environ. Sci. Technol., 36, 14141418.

9) Oberg, K., Warman, K. and Oberg, T. (2002) Distribution and levels of brominated flame retardants in sewage sludge. Chemosphere, 48, 805-809.

10) Fischer, D., Hooper, K., Athanasiadou, M., Athanassiadis, I. and Bergman, A. (2006) Children show highest levels of polybrominated diphenyl ethers in a California family of four: A case study. Environ. Health Perspect., 114, 1581-1584.

11) Harrard, S. and Porter, L. (2007) Concentrations of polybrominated diphenyl ethers in blood serum from New Zealand. Chemosphere, 66, 2019-2023.

12) Inoue, K., Harada, K., Takenaka, K., Uehara, S., Kono, M., Shimizu, T., Takasuga, T., Senthilkumar, K., Yamashita, F. and Koizumi, A. (2006) Levels and concentration ratios of polychlorinated biphenyls and polybrominated diphenyl ethers in serum and breast milk in Japanese mothers. Environ. Health Perspect., 114, 1179-1185.

13) Schecter, A., Papke, O., Harris, T. R., Tung, K. C., Musumba, A., Olson, J. and Birnbaum, L. (2006) Polybrominated diphenyl ether (PBDE) levels in an expanded market basket survey of U.S. food and estimated PBDE dietary intake by age and sex. Envi- ron. Health Perspect., 114, 1515-1520.

14) Schecter, A., Pavuk, M., Papke, O., Ryan, J. J., Birnbaum, L. and Rosen, R. (2003) Polybrominated diphenyl ethers (PBDEs) in U.S. mothers' milk. Environ. Health Perspect., 111, 1723-1729.

15) Hallgren, S. and Darnerud, P. O. (2002) Polybrominated ethers (PBDEs), polychlorinated biphenyls (PCBs), chlorinated paraffins (CPs) in rats-testing interactions and mechanisms for thyroid hormones effects. Toxicology, 177, 227-243.

16) Mariussen, E. and Fonnum, F. (2003) The effect of brominated flame retardants on neurotransmitter uptake into rat brain synaptosomes and vesicles. $\mathrm{Neu}$ rochem. Int., 43, 533-542.

17) Viberg, H., Fredriksson, A., Jakobsson, E., Orn, U. and Eriksson, P. (2003) Neurobehavioral derangements in adult mice receiving decabrominated diphenyl ether (PBDE 209) during a defined period of neonatal brain development. Toxicol. Sci., 76, 112-120.

18) Fukuda, N., Ito, Y., Yamaguchi, M., Mitumori, K., Koizumi, M., Hasegawa, R., Kamata, E. and Ema, M. (2004) Unexpected nephrotoxicity induced by tetrabromobisphenol A in newborn rats. Toxicol. Lett., 150, 145-155.

19) Hamers, T., Kamstra, J. H., Sonneveld, E., Murk, A. J., Kester, M. H. A., Andersson, P. L., Legler, J. and Brouwer, A. (2006) In vitro profiling of the endocrine-disrupting potency of brominated flame retardants. Toxicol. Sci., 92, 157-173.

20) Kitamura, S., Jinno, N., Ohta, S., Kuroki, H. and Fujimoto, N. (2002) Thyroid hormonal activity of the flame retardants tetrabromobisphenol $\mathrm{A}$ and tetrachlorobisphenol A. Biochem. Biophys. Res. Commun., 299, 554-559.

21) Olsen, C. M., Meussen-Elholm, E. T. M., Samuelsen, M., Holme, J. A. and Hongslo, J. K. (2003) Effects of the environmental oestrogens bisphenol $\mathrm{A}$, tetrachlorobisphenol $\mathrm{A}$, tetrabromobisphenol A, 4-hydroxybiphenyl and 4,4'dihydroxybiphenyl on oestrogen receptor binding, cell proliferation and regulation of oestrogen sensitive proteins in the human breast cancer cell line MCF-7. Pharmacol. Toxicol., 92, 180-188.

22) Stoker, T. E., Cooper, R. L., Lambright, C. S., Wilson, V. S., Furr, J. and Gray, L. E. (2005) In vivo and in vitro anti-androgenic effects of DE-71, a commercial polybrominated diphenyl ether (PBDE) mixture. Toxicol. Appl. Pharmacol., 207, 78-88.

23) Ceccatelli, R., Faass, O., Schlumpf, M. and Lichtensteiger, W. (2006) Gene expression and estrogen sensitivity in rat uterus after developmental exposure to the polybrominated diphenylether 
PBDE 99 and PCB. Toxicology, 220, 104-116.

24) Richardson, V. M., Staskal, D. F., Ross, D. G., Diliberto, J. J., DeVito, M. J. and Birnbaum, L. S. (2008) Possible mechanisms of thyroid hormone disruption in mice by BDE 47, a major polybrominated diphenyl ether congener. Toxicol. Appl. Pharmacol., 226, 244-250.

25) Lilienthal, H., Hack, A., Roth-Hare, A., Grande, S. W. and Talsness, C. E. (2006) Effects of developmental exposure to $2,2^{\prime}, 4,4^{\prime}, 5$-pentabromodiphenyl ether (PBDE-99) on sex steroids, sexual development, and sexually dimorphic behavior in rats. Environ. Health Perspect., 114, 194-201.

26) Sakai, H., Yamada-Okabe, T., Kashima, Y., Matsui, M., Aono, T., Aoyagi, M. and Hasegawa, J. (2003) Effects of brominated flame retardants on transcriptional activation mediated by thyroid hormone receptor. Organohalogen Compounds, 61, 215-218.

27) Zhou, T., Ross, D. G., DeVito, M. J. and Crofton, K. M. (2001) Effects of short-term in vivo exposure to polybrominated diphenyl ethers on thyroid hormones and hepatic enzyme activities in weanling rats. Toxicol. Sci., 61, 76-82.

28) Zhou, T., Taylor, M. M., DeVito, M. J. and Crofton, K. M. (2002) Developmental exposure to brominated diphenyl ethers results in thyroid hormone disruption. Toxicol. Sci., 66, 105-116.

29) Fujimoto, N., Maruyama, S. and Ito, A. (1999) Establishment of an estrogen responsive rat pituitary cell sub-line MtT/E-2. Endocr. J., 46, 389-396.

30) Kitamura, S., Ohmegi, M., Sanoh, S., Sugihara, K., Yoshihara, S., Fujimoto, N. and Ohta, S. (2003) Estrogenic activity of styrene oligomers after metabolic activation by rat liver microsomes. Environ. Health Perspect., 111, 329-334.

31) Legler, J. and Brouwer, A. (2003) Are brominated flame retardants endocrine disruptors? Environ. Int., 29, 879-885.

32) Meerts, I. A. T. M., van Zanden, J. J., Luijks, E. A. C., van Leeuwen-Bol, I., Marsh, G., Jakobsson, E., Bergman, ̊. and Brouwer, A. (2000) Potent competitive interactions of some brominated flame retardants and related compounds with human transthyretin in vitro. Toxicol. Sci., 56, 95-104.

33) Schriks, M., Vrabie, C. M., Gutleb, A. C., Faassen, E. J., Rietjens, I. M. C. M. and Murk, A. J. (2006) T-screen to quantify functional potentiating, antagonistic and thyroid hormone-like activities of poly halogenated aromatic hydrocarbons (PHAHs). Toxicol. In vitro, 20, 490-498.

34) Dietrich, S. W., Bolger, M. B., Kollman, P. A. and Jorgensen, E. C. (1977) Thyroxine analogues. 23. Quantitative structure-activity correlation studies of in vivo and in vitro thyromimetric activities. J. Med. Chem., 20, 863-880.

35) Kitamura, S., Jinno, N., Suzuki, T., Sugihara, K., Ohta, S., Kuroki, H. and Fujimoto, N. (2005) Thyroid hormone-like and estrogenic activity of hydroxylated PCBs in cell culture. Toxicology, 208, 377387.

36) Connor, K., Ramamoorthy, M., Moore, M., Mustain, M., Chen, I., Safe, S., Zacharewski, T., Gillesby, B., Joyeux, A. and Balague, P. (1997) Hydroxylated polychlorinated biphenyls (PCBs) as estrogens and antiestrogens: structure-activity relationships. Toxicol. Appl. Pharmacol., 145, 111-123.

37) Korach, K. S., Sarver, P., Chae, K., McLachlan, J. A. and McKinney, J. D. (1988) Estrogen receptor-binding activity of polychlorinated hydroxybiphenyls: conformationally restricted structural probes. Mol. Pharmacol., 33, 120-126.

38) Cheek, A. O., Know, K., Chen, J. and McLachlan, J. A. (1999) Potential mechanisms of thyroid disruption in humans: Interaction of organochlorine compounds with thyroid receptor, transthyretin, and thyroid-binding globulin. Environ. Health Perspect., 107, 273-278.

39) Iwasaki, T., Miyazaki, W., Takeshita, A., Kuroda, Y. and Koibuchi, N. (2002) Polychlorinated biphenyls suppress thyroid hormone-induced transactivation. Biochem. Biophys. Res. Commun., 299, 384-388.

40) Collins, W. T., Jr and Capen, C. C. (1980) Fine structural lesions and hormonal alterations in thyroid glands of perinatal rats exposed in utero and by the milk to polychlorinated biphenyl. Am. J. Pathol., 99, 125-142.

41) Barter, R. A. and Klaassen, C. D. (1994) Reduction of thyroid hormone levels and alteration of thyroid function by four representative UDPglucuronosyltransferase inducers in rats. Toxicol. Appl. Pharmacol., 128, 9-17.

42) Lans, M. C., Spiertz, C., Brouwer, A. and Koeman, J. H. (1994) Different competition of thyroxine binding to transthretin and thyroxine-binding globulin by hydroxy-PCBs, PCDDs, PCDFs. Eur. J. Pharmacol., 270, 129-136.

43) Morse, D. C., Klasson-Wehler, E., Wesseling, W., Koeman, J. H. and Brouwer, A. (1996) Alterations in rat brain thyroid hormone status following preand postnatal exposure to polychlorinated biphenyls (Aroclor 1254). Toxicol. Appl. Pharmacol., 136, 269-279.

44) Brouwer, A., Morse, D. C., Lans, M. C., Schuur, A. G., Murk, A. J., Klasson-Wehler, E., Bergman, A. and Visser, T. J. (1998) Interactions of persistent environmental organohalogens with the thyroid 
hormone system: mechanisms and possible consequences for animal and human health. Toxicol. Ind. Health, 14, 59-84.

45) Kuriyama, S. N., Wanner, A., Fidalgo-Neto, A. A., Talsness, C. E., Koerner, W. and Chahoud, I. (2007) Developmental exposure to low-dose PBDE99: Tissue distribution and thyroid hormone levels. Toxicology, 242, 80-90.

46) Kitamura, S., Kato, T., Iida, M., Jinno, N., Suzuki, T., Ohta, S., Fujimoto, N., Hanada, H., Kashiwagi,
K. and Kashiwagi, A. (2005) Anti-thyroid hormonal activity of tetrabromobisphenol A, a flame retardant, and related compounds: Affinity to mammalian thyroid hormone receptor, and effect on tadpole metamorphosis. Life Sci., 76, 1589-1601.

47) Goto, Y., Kitamura, S., Kashiwagi, K., Oofusa, K., Tooi, O., Yoshizato, K., Sato, J., Ohta, S. and Kashiwagi, A. (2006) Suppression of amphibian metamorphosis by bisphenol A and related chemical substances. J. Health Sci., 52, 160-168. 